\title{
Discovery on the Artistic Expression of Georgette through Silk Painting
}

\section{Jui-che Tu*}

National Yunlin University of Science and Technology, Taiwan

\begin{abstract}
The unique woven structure and special fabric texture of georgette make georgette-painting practice unparalleled compared with many other silk painting practices. This study aims to discover the artistic expression of georgette from four aspects: subjects for georgette painting, forms of georgette painting, colors of georgette painting and textures of georgette painting. Experimental hand painting practices and comparisons are carried out as study methods. This paper finds out: the subjects for georgette painting is closely associated with the feature of fabric; the feature of georgette fabric may limit the delicacy of painted patterns; the colors for georgette painting could present imaginational and mysterious artistic blending and transformation; thorny lines and zigzag pattern edges are two of georgette-painting textures. Besides art area, painted georgette fabric could be further applied for design areas such as garment design, accessory design and space decoration design.
\end{abstract}

Keywords: Artistic expression; Silk painting; Feature of georgette

\section{Introduction}

Georgette fabric is a plain weave textile woven by raw silk. The weft and warp of georgette fabric are combined with pieces of highly twisting mulberry silk, with the twisting degree of more than $2000 \mathrm{~T} / \mathrm{m}$. Owing to this feature, georgette fabric could own a wrinkled visual effect and a slightly rough touch feeling. The special fabric structure and unique texture make georgette distinguished from other silk category, and also provide a creative platform for artistic expression through silk painting practice. Hand painting has a long history and a high reputation for fabric decoration [1]. Hand painting on georgette fabric can strongly enhance the unique feature and inherent charm of georgette by proper techniques and methods. The final visual effects of georgette painting are unparalleled compared with other types of silk painting [2].

This study will discover the artistic expression of georgette by hand painting practices and comparisons. The physical specifications of the painting georgette are measured (Table 1).

\section{Artistic Expression of Georgette}

\section{Subjects for georgette painting}

The subjects for georgette painting are closely associated with the feature of fabric. The structure of georgette fabric is relatively loose and bouncy, so the overall appearance of georgette is transparent, lightweight, soft and flowing, which makes georgette a favorable and popular fabric for female fashion owing to its attractive feminine nature. Accordingly, characteristics of patterns for georgette painting are usually in accordance with this dreamy feeling, conveying a relaxing and pleasant message. In affluent society, although patterns for silk painting are constantly updating to be more market adaptable [3], some classic patterns could still be reminiscent and emotional [4]. Patterns for georgette painting may change with fashion trend and aesthetic taste, but their subjects are mainly focused on some popular patterns such as floral pattern, paisley pattern and geometrical pattern. Floral pattern is a timeless subject, which represents people's eternal pursuit for beautiful things; Paisley pattern is an exotic pattern but quickly

\begin{tabular}{|c|c|c|c|}
\hline Warp Combination & \multicolumn{3}{|c|}{ 23dtex $\times 2$ raw silk $3000 \mathrm{~T} / \mathrm{m} \mathrm{2S2Z}$} \\
\hline Weft Combination & \multicolumn{3}{|c|}{ 23dtex $\times 2$ raw silk $3000 \mathrm{~T} / \mathrm{m} \mathrm{2S} 2 \mathrm{Z}$} \\
\hline $\mathrm{P}_{\mathrm{j}} /\left(\right.$ Threads $\left.\cdot 10 \mathrm{~cm}^{-1}\right)$ & 520 & $\mathrm{P}_{\mathrm{w}} /\left(\right.$ Threads $\left.\cdot 10 \mathrm{~cm}^{-1}\right)$ & 440 \\
\hline Fabric Structure & Plain Weave & Unit Weight $/\left(\mathrm{g} \cdot \mathrm{m}^{-2}\right)$ & 33 \\
\hline
\end{tabular}

Table 1: Physical specifications of the painting georgette. and well received by Chinese people, embodying grace and elegance; Geometrical pattern is widely spread nowadays as a symbol for simple and modern life. When these patterns are painted on georgette, it seems that culture and art are harmoniously blended, an artistic prospect commonly appreciated by Chinese people. The difference between subjects for georgette painting and other silk painting may lie in the complexity of pattern combination. For georgette painting, there is may be one subject, while for other silk painting such as satin painting, there could be multiple subjects combined together.

\section{Forms of georgette painting}

Some features of georgette such as crepe-like texture give the fabric a bouncy and flowing look, but could also limit the delicacy of patterns from another angle. First, it is relatively hard to paint delicate patterns. The structure of georgette fabric is a little bit looser compared with many other silk fabrics. With the stretch of external forces, the fabric extends, followed by the widening space between weft and warp threads. On this status, the painting surface seems to be a canvas with numerous tiny holes, which makes details of patterns difficult to depict. Take floral pattern for example, when painting on some tightly woven silk such as satin, details are easier to display. But when it comes to georgette fabric, the structures of flowers and plants usually need to be summarized or simplified. In general, patterns on georgette fabric seem to be more abstract while patterns on thicker and smoother fabric are usually more detailed. Second, it is challenging to maintain the shape of pattern. Since the structure and appearance of georgette fabric change with different forces of stretch, when painting on georgette, the fabric is largely stretched into a nearly flat surface and temporarily fixed, which offers a flat 'canvas' to paint patterns. When painting is completed and external force disappears, the fabric relaxes and gradually shrinks to wrinkle status, directly leading to the 'distortion' of patterns to some extent. Accordingly, originally painted patterns change with outer

*Corresponding author: Xiu-yue Zhang, National Yunlin University of Science and Technology, Taiwan, Tel: 8865534 2601; E-mail: xiuyuezhang2013@gmail.com

Received September 23, 2016; Accepted October 05, 2016; Published October 12, 2016

Citation: Zhang XY, Tu JC (2016) Discovery on the Artistic Expression of Georgette through Silk Painting. J Textile Sci Eng 6: 271. doi: 10.4172/2165-8064.1000271

Copyright: ( 2016 Zhang XY, et al. This is an open-access article distributed under the terms of the Creative Commons Attribution License, which permits unrestricted use, distribution, and reproduction in any medium, provided the original author and source are credited. 
forces and status of fabric: straight lines could turn into curving lines or zigzag lines; circular patterns may turn into oval patterns; patterns seem to be exaggerated or simplified by fabric shrinking in different degrees (Figure 1).

\section{Colors of georgette painting}

The color presentation on georgette fabric is special. First, the color is visually 'humbled. The loose and thin georgette fabric could limit the absorbing amounts of dying. Moreover, the surface of georgette is uneven and rough, physically making it easier to do the diffuse reflection. Consequently, the colors on georgette are visually more humbled and more implicit compared with some thicker and tightly woven silk fabrics such as satin, the shiny sheen and luxurious luster surface of which could greatly enhance the painting color, making it bright and sparkling (Figure 2). No matter how bright and how pure the dying looks like, the color always seems to be softly presented on georgette-gentle, elegant and peaceful- as if covered with a layer of mist, especially when the fabric is wrinkled. This quality may echo with traditional Chinese value of modesty, humble and elegance. Second, the color is visually 'blending. Without flamboyant color appearance, the visual effects of painted georgette could still be splendid. When soft and wrinkled georgette relaxes, color arrangements are simultaneously presented through uneven surfaces and rich textures, leading to a natural color mixture and blending. What's more, since georgette is half transparent, colors painted on georgette are consequently overlapping in different layers when the fabric folds and overlaps, creating sophisticated grayness and darkness. According to different status of fabric, delicate color tunes could change magically and unpredictably, presenting a kaleidoscopic look and mysterious color mixture (Figure 3). Another thing to mention is that georgette fabric can be easily dyed in a myriad of colors with least amounts of dying, which is eco-friendly to some extent.

\section{Textures of georgette painting}

As a kind of artistic language, the creation of textures is connected with specific medium and techniques [5]. There are two typical textures when painting on georgette fabric: thorny lines and zigzag pattern edges. Since the fiber of georgette fabric is woven highly twisted, dying could quickly penetrate into fabric through the trace of twisting fibers, creating irregular twisting lines. The flowing dying trace is quite intricate and unpredictable, the shape of which seems like numerous distorted tiny branches and slim roots (Figure 4). At a distance, the naturally created texture of lines could be described as thorny, which is rarely seen on other silk painting. When large amounts of dying are applied to georgette, some irregular patterns are naturally created, similar to other silk painting. The difference lies in the edges of different patterns and shapes. For georgette painting, the edge is rough, more like a zigzag shape, while it is smoother on some other silk fabrics (Figure 5). Moreover, owing to the highly absorbent and penetrating nature of georgette fabric, two sides of georgette could easily and quickly present similar or even identical textures if the amount of dying is enough [6]. With the complement of wrinkled texture of georgette fabric, textures of georgette painting could enhance the artistic expression of georgette through various thorny lines and silhouette of different patterns.

\section{Application of Georgette Painting}

\section{Garments Made of Painted Georgette Fabric}

Based on the discovery of artistic expression of georgette painting, application of georgette painting could be more specific, such as application to fashion industry. Taking function into consideration, garments made of painted georgette fabric are very intimate to the skin, highly breathable and hygroscopic, which can help regulate the body temperature and lead to a comfortable sensation. Taking visual effects
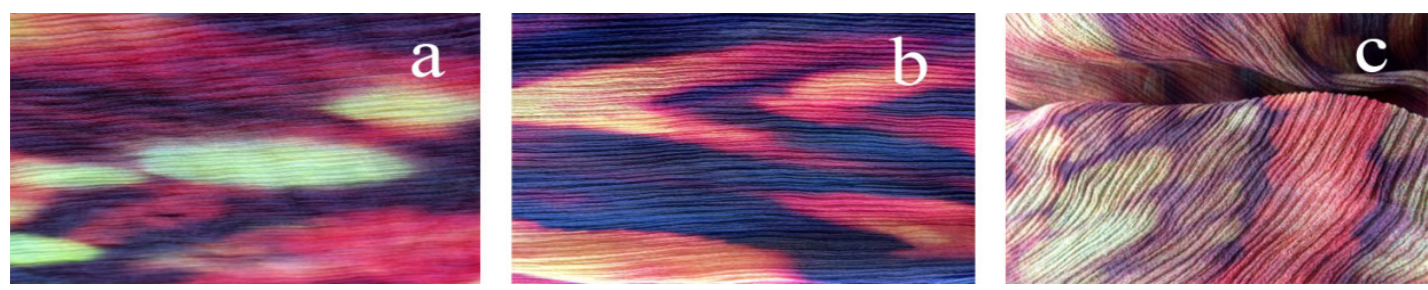

Figure 1: Different shapes on georgette (self-painted) (a) Oval shape (b) Sharp shape (c) Curving shape.
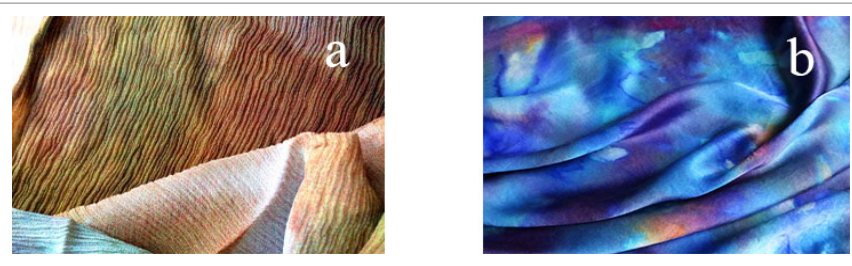

Figure 2: Color presentation on two fabrics (self-painted) (a) Color presentation on georgette (b) Color presentation on satin.
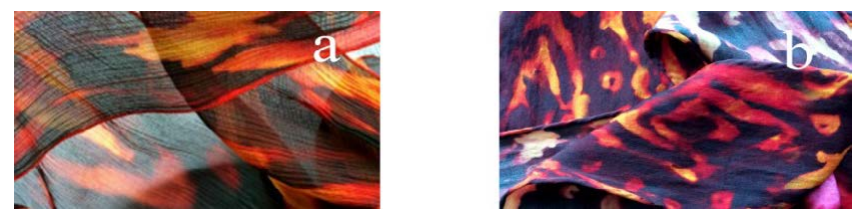

Figure 3: Color overlays on two fabrics (self-painted) (a) Color overlays on georgette (b) Color overlays on satin.
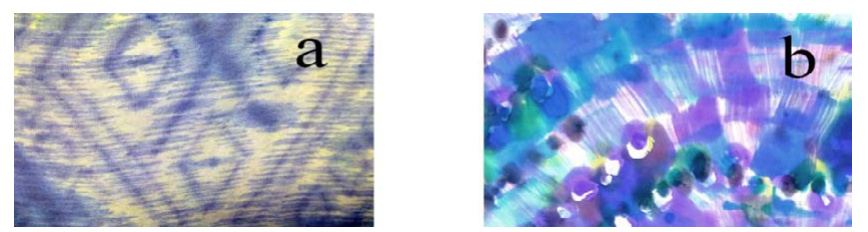

Figure 4: Texture of lines on two fabrics (self-painted) (a) Texture of lines on georgette (b) Texture of lines on crepe de chine.
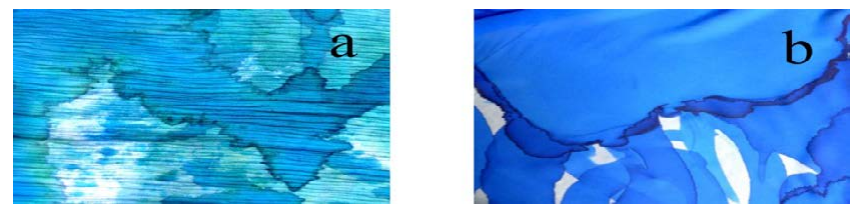

Figure 5: Texture of edges on two fabrics (self-painted) (a) Texture of edges on georgette (b) Texture of edges on plain satin. 
into consideration, garments made of painted georgette fabric are naturally wrinkled and bouncy, which makes them look very feminine and still stay cool and light to wear. Taking consumer psychology into consideration, the unique texture and pattern could echo with some consumer's demand for being special and showing their aesthetic tastes [7], while hand painting method echoes with fashion trend of individuation and customization. It seems that georgette fabric is well received in female fashion, but it may also own a place in male fashion. The feminine quality of georgette could bring a contrast to the tough masculinity, enriching the style and category for men's wear.

\section{Accessories made of painted georgette fabric}

Besides diverse application to clothing such as shirts, trousers and dresses, georgette fabric is also popular for accessories especially silk scarves. Georgette scarf may protect human body as well as decorate it. When wound around the neck or on the shoulder, georgette scarf can keep these vulnerable parts warm and thus make human body comfortable. In terms of decoration function, the color matching and knotting methods are two important aspects, which should be in accordance with the garments to present an overall look. Taking color matching for example, when matching with monochrome garments, especially black clothing, colorful patterned georgette scarf may well light up the whole look and make the wearer look more energetic. When matching with similar color tune, it may bring a humble and elegant feeling. When matching with contrast color, which is challenging, the wearer's strong personality may be strengthened. Since georgette scarf has different sizes and shapes, knotting methods could change flexibly and creatively according to the style and color of garments. In addition, painted georgette fabric could be designed for other accessories such as hair decoration, hand decoration and ties.

\section{Space decoration made of painted georgette fabric}

Not only is painted georgette fabric intimate to human body, it is also exploitable to human's activity space such as home and public space [8]. At home, painted georgette fabric could be used as decorations or materials for home textiles such as pillows, curtains, rugs and blankets. It could also be part of home furniture such as folding screens, dividing space as well as decorating space in an artistic way. Besides, it could be framed and hanged on the wall as an artifact to appreciate. In some public space, soft and feminine feature of painted georgette could add a touch of warmth, coziness and softness to cold and empty space, and mentally influence people's emotion through visual communication.

\section{Conclusion}

Through georgette painting practice, the artistic expression of georgette could be further discovered and enhanced:

- The subjects for georgette painting are closely associated with the feature of fabric;

- Owing to the fabric stretch and wrinkle, patterns presented on georgette through hand painting may be out of shape to some degree, thus the feature for georgette fabric may limit the delicacy of patterns;

- The colors of dying on georgette are magically diversified and greatly sophisticated by visually blending with irregular uneven fabric surfaces and random fabric overlapping, contributing to an imaginational and mysterious artistic blending and transformation;

- Thorny lines and zigzag pattern edges could be typical georgette painting textures;

- The overall artistic visual effects of georgette painting are graceful, elegant and mild.

All these artistic features of georgette painting make it a special choice for design endeavor, which can tremendously enrich people's life.

\section{References}

1. Yuan XP, Qiu HS (2006) History and Tradition of Silk Painting. Silk 45-48.

2. Dong FC (2003) Study of Spattering Dye Process of Silk Georgette. Journal of Henan Textile College 16: 7-8.

3. Cheng $X$ (2011) Thoughts on the creative design of hand-painted Silk. Silk 48 35-39.

4. Ren JP, Zhang CJ, Chen YH (2007) Character of Modern Silk Painting and Creative Design. Silk 14-18.

5. $\mathrm{Wu} \mathrm{HH}$ (2012) Study of the artistic performance of texture in silk hand-painting Silk 49: $37-40$

6. Miao LY, Zhang XX (2008) Study on silk painting. Journal of Nanjing Arts Institute 145-147.

7. Qiu HS, Yuan XP and Yang J (2009) The technic and market of contemporary silk painting products. Silk 9-12.

8. Lin YZ (2002) Silk Hand Drawing. Journal of Zhejiang Institute of Science and Technology 124-127. 